\title{
Representaciones de género y juventud en el discurso radiofónico: andro-hetero-sexismo comunicacional mediatizado sobre las y los jóvenes
}

Representations of gender and youth in the radio address : andro-hetero-

mediated on communicative sexism and youth

- Paula Morales Monguillot

Centro de Estudios Avanzados (CEA-UNC), Universidad Nacional de Córdoba (Argentina)

Fecha de recepción: 26 de marzo

Fecha de aceptación: 6 de junio de 2015

DOI: http://dx.doi.org/10.15304/ricd.1.2.2492

\section{Resumen}

Este artículo presenta un enfoque de investigación sociodiscursiva aplicada a los medios de comunicación. La metodología de análisis es de carácter cualitativa y se inscribe en la intersección entre los Estudios de Género, los Estudios de Juventud, y los de Comunicación, para analizar los modos de aparición de lo juvenil, desde las condiciones de enunciación de un medio muy poco estudiado: la radio.

En el mismo nos proponemos entender las particulares modalizaciones que ejercen los medios de comunicación (en particular la radio) sobre las representaciones juveniles - desde una perspectiva de género-, entendiendo la juventud como una dimensión particular de análisis en esta red semiótica de violencias mediáticas, mediante un análisis del discurso radiofónico emitido por Radio LV3 y Radio Nacional Córdoba durante las segundas mañanas ( 8 a 12 hs) del 21 de septiembre de 2011 ("Día del Estudiante" y "Día de la Primavera”).

\section{Abstract}

This paper presents an approach to applied research sociodiscursiva media. The analysis methodology is qualitative in nature and it's part of the intersection between gender studies, Youth Studies, and Communication, to discuss ways of developing the youth, since the conditions of enunciation of an average little studied: the radio.

In the same we intend to understand the modalizations individuals exercising the media (especially radio) on youth representation -from the perspective of genre-, understanding youth as a particular dimension of this semiotic analysis of media violence network, by analyzing the radio speech broadcast by Radio National Radio LV3 and Cordoba during the second morning ( 8-12 hours) of September 21, 2011 (Sstudent Day “ and "Day of Spring”) .

\section{Palabras clave}

Representaciones de género, discurso radiofónico, juventud. 


\section{Keywords}

Representations of gender, Radiophonic discourse, youth.

\section{Sumario}

1. Introducción

2. Estado de la cuestión

2.1. La condición juvenil en América Latina del siglo XX al XXI

2.2. Los estudios en comunicación radiofónica desde una perspectiva de género.

3. Jóvenes y mediatización

3.1. La construcción del sentido sobre la condición juvenil

3.2. Las tendencias en los estudios sobre juventud

3.3. Los estudios sobre juventud y la perspectiva de género

4. Nuestra perspectiva de análisis y enfoque metodológico

4.1. Andro-hetero-sexismo comunicacional mediatizado

4.2. Radio, Género y Juventudes. Una articulación novedosa

5. Lo juvenil en radio: las representaciones de género en 'Día del estudiante' y 'Día de la primavera'

5.1. Temas y relaciones de género

6. Conclusiones

\section{Contents}

1. Introduction

2. State of the art

2.1. The condition of youth in Latin America from the twentieth century to the XXI.

2.2. Studies in radio communication from a gender perspective

3. Youth and mediation

3.1. The construction of meaning on the condition of youth

3.2. Trends in youth studies

3.3. Studies on youth and gender

4. Our analytical perspective and methodological approach

4.1. Andro-Mediated Hetero-sexism Communicative

4.2. Radio, Gender and Youth. A new joint

5. The youth in radio: gender representations of 'Student Day' and 'Day of Spring'

5.1. Issues and gender relations

6. Conclusions 


\section{INTRODUCCIÓN}

Los procesos de convergencia mediática, con sus lógicas de hipertextualidad, interactividad y multimedialidad, han complejizado las formas de producción y consumo discursivo que regulan aspectos concretos de las relaciones sociales, particularmente aquellos que atañen a los jóvenes, en los procesos de subjetivación, de consumo y de identificación que vivencian cotidianamente. Estamos en una época de mediatización global y multimedial.

En este artículo nos preguntamos por la construcción de inteligibilidades sobre la condición juvenil generizada y lo hacemos a través de los sentidos que construyen mediáticamente algunos discursos radiofónicos (que describiremos prontamente). Hacemos un corte sincrónico del magma de sentidos que circulan, que se publican, y se emiten en un momento dado, para reconocer allí -en ese recorte doxástico (Angenot, 2010)- las tópicas y retóricas desde las cuales el sistema mediático construye enunciaciones situadas, posicionamientos, señalamientos y distinciones sobre lo que es juvenil y lo que no lo es; y sobre las correspondencias sexo-genéricas que de allí se desprenden cada vez que se clasifica de diversas maneras el ser jóvenes, y se atribuye credibilidad o desconfianza sobre los colectivos juveniles.

En una palabra, queremos ver cómo se construyen sentidos sobre lo juvenil y las juventudes desde la radio, porque nos preocupa la construcción de diferencias en el contexto de la reproducción de desigualdades, ya que partimos de la hipótesis de Sanchez Leiva (2007) que alerta sobre aquellos procesos (comunicacionales) donde algunas diferencias se tornan significativas y estigmatizantes y producen lo que podríamos Ilamar márgenes de diferenciación excluyente para los sujetos juveniles en función de su condición sexo-genérica.

El artículo se inscribe en el proyecto de investigación doctoral titulado "Violencia Mediática: un abordaje socio semiótico sobre el tratamiento del género en el discurso radio- fónico", y pretende recuperar buena parte de las discusiones y producción teórica emergentes del proyecto de investigación "Discursos juveniles en la cultura urbana contemporánea: mediatización y cuerpos", y sus anteriores "Prácticas comunicativas juveniles en la tecnocultura contemporánea: hegemonías y heteronomías" y "Mediatización y prácticas comunicativas juveniles: espacios de poder y resistencia en la discursividad contemporánea (I y II)".

Esta investigación se inscribe en un campo emergente para los estudios latinoamericanos en comunicación, el de los estudios en comunicación con perspectiva de género, y es precisamente allí donde nos interesa generar un cruce teórico - pero también metodológico-, para abordar las subjetividades juveniles generizadas.

En el diseño de un abordaje metodológico para la tesis doctoral citada, definimos trabajar sobre la materialidad sonora del discurso radiofónico, y construimos un corpus conformado por emisiones radiales de dos instituciones locales, en sus puestas al aire durante los meses de septiembre y noviembre de 2011, y marzo de 2012, durante las segundas mañanas (8 a 13 hs). Allí, nos ubicamos en el género periodístico magazine e identificamos los segmentos que correspondiesen al género discursivo dialogal donde predominan pasajes de conversación, opinión, información y entretenimiento. ${ }^{1}$

Uno de los dos programas analizados, Juntos, se escucha diariamente por LV3, emisora de más de 30 años al aire, integrante del multimedio Cadena 3 Argentina, con repetidoras en todo el país y los más altos índices de audiencia por AM ( 255.000 oyentes según mediciones de lbope en 2015). En Córdoba emite a través de las frecuencias AM 700 y FM 106.9

Por su parte, el programa radial de AM 750 Radio Nacional Córdoba, La Romería, es un magazine co-conducido por el trío mediático de los Romero (María Esther y José Luis) y Sergio Tagle, y cuenta con una audiencia fidelizada que podríamos definir en un cronolecto adulto y culto, con alta formación política y

\footnotetext{
${ }^{1}$ Además de tomar los pasajes de la conversación dialogal en estudio, en la muestra seleccionada definimos por Unidad de Análisis (UA) aquellos segmentos o piezas radiofónicas cuya particularidad reviste en el tratamiento en profundidad de un tema de interés y el despliegue de múltiples estrategias argumentativas para su abordaje. Nos referimos así a las Columnas de opinión, y Mesas de Café o Tertulias, y las complementamos con la UA del género participación Llamados de oyentes.
} 
participación ciudadana. ${ }^{2}$

En base a las 728 horas de nuestro universo muestral (estos programas magazines), seleccionamos 120 horas, siguiendo el criterio de fechas claves (14 de septiembre, Día Latinoamericano de la Imagen de la Mujer en los Medios de Comunicación; 25 de noviembre, Día Internacional contra la Violencia hacia las Mujeres y 8 de marzo, Día Internacional de la Mujer Trabajadora). Complementamos las mismas con el análisis de dos emisiones de la semana previa (y dos posteriores) a cada fecha clave.

Para este artículo seleccionamos una pequeña muestra del corpus correspondiente a las segundas mañanas (8 a 12 hs), del 21 de septiembre de 2011 (Día del estudiante y Día de la primavera) para abordar las representaciones de las relaciones de género (López Diez, 2005) que construyen diferencias y desigualdades juveniles. Estas representaciones operan por acción y también por omisión (como todas las violencias de género) y es precisamente allí, en las representaciones silenciadas e invisibilizadas (Ammann y Da Porta, 2011) por el discurso mediático, pero también en las hiperrepresentaciones juveniles generizadas, que podremos ver como opera el andro-hetero sexismo comunicacional mediatizado sobre las juventudes.

Ambas emisoras - de alto alcance provincial-, no priorizan al público juvenil en los contratos de lectura propuestos con sus oyentes (Eco, 1979). Así, la enunciación mediatizada que desde ellas se emite se ubica en determinadas condiciones estructurales sobre lo que los adultos construyen discursivamente alrededor de nociones como juventud y juvenil, y a su vez se inscribe en el marco de lo que Balardini describe como procesos intersubjetivos inscritos en relaciones sociales e históricas situadas, en el contexto social y en su relación con lo no juvenil (Balardini, 2004).

\section{ESTADO DE LA CUESTIÓN}

\subsection{LA CONDICIÓN JUVENIL EN AMÉRICA LATINA DEL SIGLO XX AL XXI}

Para hablar sobre juventud/es debemos decir que hay diversas matrices culturales que sustentan las miradas y los discursos sobre la/s juventud/es, y que dichas matrices dan cuenta de una construcción sociocultural que sitúa a este grupo social -a través de sus producciones y reproducciones-, de manera cronotópica y a partir de una mirada adultocéntrica y sexista. En el recorte discursivo que emprendamos, se nos presentarán entonces una serie de trampas discursivas a deconstruir.

La categoría juventud o juventudes con las que trabajamos corresponden al sociólogo chileno Duarte Quapper (2000) y ambas acepciones son por él empleadas para definir a los sujetos jóvenes en tanto grupo social, categorizado desde distintas variables (demográficas, económicas, culturales, etc.). Por su parte, Quapper hablará de lo juvenil para referirse a las producciones culturales y contraculturales que estos grupos sociales despliegan o inhiben en su cotidianeidad.

El carácter político del surgimiento de la categoría juventudes en Latinoamérica debe situar nuestros análisis. Cuando elegimos abordar una fecha -por ejemplo el 21 de septiembre, reconocido como el Día del Estudiante-, no podemos desconocer la significación de esta, en relación a los contextos de lucha y reivindicación estudiantil en la región. Rossana Reguillo (2000) sitúa sus estudios sobre juventudes describiendo la irrupción de los jóvenes en la escena pública contemporánea latinoamericana, en relación con lo ocurrido en otros lugares del mundo, tomando como punto de partida la época de los movimientos estudiantiles de finales de la década de los sesenta.

Desde este puntapié decimos entonces -en consonancia con Reguillo-, que en los 70, los "estudiantes" simbolizaban un actor social que tendía a ser visto con temor o con romanticismo, pero que sin lugar a dudas mostraba una firme voluntad de participar como actor político. En síntesis: rebeldes, estudiantes revoltosos, subversivos, delincuentes, y violentos (Reguillo, 2000).

Apuntará la autora que, en América Latina, los movimientos políticos que intentaron llevar adelante transformaciones sociales, sufrieron una dura derrota política. Hacia los años ochenta los sentidos pos dictadura en

\footnotetext{
${ }^{2}$ Las emisoras mencionadas se encuentran físicamente ubicadas en la ciudad de Córdoba, provincia de Córdoba, Argentina, desde donde retransmiten sus contenidos vía web por Cadena3.com.
} 
torno a los cambios sociales y las utopías perdieron fuerza, y se produjo un fuerte repliegue de las y los jóvenes hacia la esfera de la vida privada. Esto generó que en el campo político las acciones de los sectores juveniles se volvieran prácticamente invisibles (Reguillo, 2000).

Florencia Saintut (2005) describe el clima de época que dio lugar a esas imágenes de jóvenes en una América Latina que se disputaba entre la impugnación de órdenes dominantes y la represión estatal, contexto de revoluciones y dictaduras. Allí los jóvenes se posicionaban en la vanguardia de nuevos valores sociales articulando política, economía, cultura, sexualidades, etc. Será en los años 80 cuando el Estado mirará a estos jóvenes como protagonistas posibles del nuevo proceso de restauración democrática (sin pasado, o negándolo para construir "futuro") y elaborará una serie de mecanismos institucionales que -racionalmente y al amparo de las instituciones-, sentaran las bases de una nueva democracia con sus correspondientes nuevos actores, para dar lugar a la década del 1990 marcada por una fuerte exclusión social y desilusión política.

En este contexto el siglo XXI es un escenario que obliga a las juventudes a una reconfiguración profunda y se presenta cargado de tensiones y conflictos. Siguiendo la tesis sobre las "paradojas" planteada por Martín Hopenhayn (2011), podemos decir que hay muchas juventudes, y que tanto la inclusión social como el sentido de pertenencia tienen peso distinto en cada una de ellas. Las juventudes entonces estarán atravesadas por cuatro tensiones o paradoja:

1. La primera se basa en que la juventud goza de más acceso a la educación, hay más años de escolaridad formal que en generaciones precedentes, pero menos acceso al empleo.

2. La segunda señala que los jóvenes gozan de más acceso a la información y menos acceso al poder, y por ende participan menos de los espacios decisorios de la sociedad.

3. La tercera tensión afecta a todos los grupos de edad, pero lo hace más intensamente en los jóvenes. Es la desproporción entre consumo simbólico y consumo material, considerando que el aumento de consumo simbólico genera, a su vez, más expectativas de consumo material.

4. La cuarta consiste en el desarrollo de más destrezas para la autonomía y menos opciones para materializarla (2011, pp. 284286).

Nos ubicamos en el contexto de Argentina, país en el que, tal como lo señalan Kessler y Merklen (2013), la recuperación de la actividad económica ha provocado "una ruptura entre el mundo desolado que dejaron los años noventa y la situación actual". Sin embargo, estos autores señalan también que esa recuperación no ha logrado que el empleo protegido y estable todavía sea accesible para una parte importante de los sectores populares. En relación con su mirada sobre los jóvenes, coincidimos en que: "De un modo mucho más extendido, el horizonte de los jóvenes, es decir, de aquellos que pugnan por llevar una vida autónoma o formar una familia, criar a sus hijos, ingresar en la vida adulta y en el mercado de trabajo, se proyecta masivamente hacia la experiencia de la inestabilidad" (2013, pp. 13-14).

Como indica el proyecto de investigación que desarrollamos actualmente: "Discursos juveniles en la cultura urbana contemporánea: mediatización y cuerpos" (2014/2016 SECYT-UNC):

(para la juventud) Se han amplificado las posibilidades de intervenir en la trama comunicacional a través de la participación en diversas plataformas y redes sociales. Sin embargo, esa notable reconfiguración del espacio-tiempo social no se produce al margen de divergencias en las relaciones global-local, público-privado; así como tampoco de importantes zonas de la vida social (...) se han generado nuevas situaciones de privación relativa, exacerbación de las diferencias y, más en general, una centralidad del mercado y de las expectativas de consumo.

La Encuesta Iberoamericana de Juventudes (2013) -basada en 20.000 encuestas realizadas en 20 países de la región-, aborda los problemas y expectativas de la juventud y las políticas de los gobiernos sobre esta problemática; describe a la juventud como compleja, diversa y desigual. En una entrevista realizada para el periódico Página 12 (2013), Alejo Ramírez (Lantos, 2013) explica:

La juventud es compleja porque hay paradojas: es la generación más formada y a la 
vez la que más desempleados tiene, es global pero también migra; es diversa porque las realidades son muy distintas, entre el campo y la ciudad, el que tiene acceso a la educación universitaria y el que no, que más que una juventud se puede hablar de juventudes, y el tercer punto tiene que ver con la desigualdad que es un eje transversal que atraviesa a toda la juventud. En ese contexto, mi análisis es que los gobiernos del Cono Sur han comprendido mejor que nadie eso, y desde ahí han planteado un vínculo muchas veces directo entre los jefes de Estado y las juventudes. Primero se comprendió y después se dialogó. No se fue sobre lugares comunes. Se abrieron canales de participación y de comunicación y eso se plasma no solamente en dejar algunos cargos clave en manos de jóvenes sino también en políticas públicas.

Asimismo, desde la Organización Iberoamericana de Juventud se destacan algunas políticas públicas en relación con la juventud, que en el caso argentino referencian a los planes Conectar Igualdad y la Asignación Universal como iniciativas destacables porque "parten de la premisa de que no solamente es necesario invertir en los jóvenes sino que en ese proceso los jóvenes tengan protagonismo" (2013).

\subsection{LOS ESTUDIOS EN COMUNICACIÓN RADIOFÓNICA DESDE UNA PERSPECTIVA DE GÉNERO}

La investigación sobre las radios cordobesas que da pié a este artículo se inscribe en un contexto de mediatización y cambios respecto de las legislaciones y políticas de comunicación en la región, ${ }^{3}$ como parte de un diálogo que le precede pero que -al mismo tiempo-, es condición que habilita la emergencia de nuevas preguntas en el campo de las ciencias sociales y humanas. Nos referimos al emergente campo de los estudios de
Comunicación Sociodiscursiva en Radio con Perspectiva de Género en la región latinoamericana. Este es un campo incipiente, y no son muchos los estudios al respecto.

A nivel iberoamericano la Dra. López Diez realizó en 1996 su tesis doctoral y analizó magazines radiofónicos desde la perspectiva de género. Además fue quien posteriormente diseñó e implementó la transversalización de género en los servicios de Radio y Televisión Española, editando al respecto dos informes de envergadura y publicaciones de referencia sobre las representaciones de género en los informativos de Radio y TV (López Díez (Dir.), 2001 y 2005). ${ }^{4}$

Generalmente, los estudios que articulan radio y sociosemiótica analizan discursivamente la materialidad sonora y describen contenidos y tratamientos, como es el caso de Diana Munguia Chirino (2012), que investiga sobre el discurso amoroso en radio a través del análisis de cancione, o María Martínez Lirola (2011), quien aborda la construcción discursiva de mujeres y menores inmigrantes en noticias radiofónicas. Por otro lado encontramos estudios que proponen un abordaje del lenguaje radiofónico y del medio desde una perspectiva sociosemiótica (Balsebre, 1994; Fernández, 2008), pero ninguno de los precedentes realiza la articulación entre el género, la sociosemiótica y la radio.

Nuestras poblaciones latinoamericanas siguen consumiendo $-\mathrm{y}$ cada vez más, produciendo- contenidos radiofónicos. La última Encuesta Nacional de Consumos Culturales y Entorno Digital de Argentina ${ }^{5}$ (2013) indagó acerca de los gustos, las preferencias, los usos y las percepciones y las valoraciones de los argentinos respecto de la cultura en general, y de los consumos culturales en particular, e indica que el $86 \%$ de la población encuestada escucha radio y el promedio de horas de escucha va de 1 a 3 diarias.

En el campo de los debates públicos, la radio se ubica aún en un papel de vigencia en nuestras sociedades latinoamericanas, y

\footnotetext{
${ }^{3}$ A nivel nacional, fue a partir de la sanción de dos leyes nacionales como la Ley 26485 de Protección Integral para prevenir, sancionar y erradicar la violencia contra las mujeres en los ámbitos en que se desarrollan sus relaciones interpersonales , y la Ley 26522 de Servicios de Comunicación Audiovisual que contamos con un artículo específico sobre la VM (en la primera) y otros complementarios que le dan extensión (en la segunda). La Ley 26485 es la segunda normativa de la región sudamericana en incorporar la categoría de Violencia mediática (VM).

${ }^{4}$ Otros antecedentes en el tema son: el informe andaluz (Consejo Audiovisual de Andalucía, 2013) sobre la distribución por sexo de los tiempos de palabra en los informativos de las televisiones públicas andaluzas, editado en 2010 por el área de contenidos del Consejo Audiovisual de Andalucía, que sienta precedentes para posteriores análisis en el campo radiofónico.

${ }^{5}$ Elaborada por la Secretaría de Cultura de la Nación, Sistema de Información Cultural de la Argentina.
} 
aún más, de relevancia, ya que trabaja con la palabra y -a su favor y diferencialmente con otros medios- es en el juego del lenguaje radiofónico, entre la palabra y el silencio, donde se despliega un particular matiz de contacto y reconocimiento que podemos anticipar en el orden de lo indicial (el cuerpo, la humanización y corporeización de los discursos sociales) y el de la cotidianeidad y sus temporalidades constitutivas. A su vez, los índices de violencias de género constituyen hoy un indicador de urgencia en nuestra región (con datos significativos de violencia hacia mujeres jóvenes), y los datos arrojados por el último informe (2010) del Proyecto Monitoreo Global de Medios, ${ }^{6}$ todos indicadores de relevancia para la investigación y tratamiento de la problemática de las Violencia Mediática de Género (VMG) en radio.

\section{JÓVENES Y MEDIATIZACIÓN}

\subsection{LA CONSTRUCCIÓN DEL SENTIDO SOBRE LA CONDICIÓN JUVENIL}

Entendemos por género tanto una categoría explicativa (Scott, en Lamas 2003) como una perspectiva. En el sentido categorial interpretamos por tal una forma primaria de relaciones significantes de poder, situada socio históricamente (2003, p. 330), que funciona como categoría explicativa que permite visibilizar un sistema de relaciones (Izquierdo, 1994, p. 48) que -en función de una división sexual y jerárquica-, se organiza, se divide simbólicamente y se vive empíricamente. Este sistema de relaciones es conocido como sistema sexo-género y su potencial se presenta en el grado de naturalización que adquiere a través de lo que Butler denomina "rejilla de inteligibilidad cultural" (2001, p.38).

El concepto de Matriz de inteligibilidad Mediática que hemos elaborado desde esta perspectiva de género parte de la concepción de matriz de inteligibilidad butleriana, y previo a ella, bajtineana. Para Butler, la marca de inteligibilidad es aquella que portamos los seres humanos, y que es al mismo tiempo la condición de existencia por la cual un otro registra nuestra existencia también. Esta marca se elabora en función de normas de in- teligibilidad que presentan coherencia y continuidad, y cuya consecuencia es una relación política instituida por esas mismas leyes culturales, que establecen y regulan la forma y el significado de la sexualidad (Butler, 2001).

Estas maneras de pensar la humanidad a través de la búsqueda de coherencias y continuidades entre las variables sexo-génerodeseo -y entre muchos otros términos en el marco de esta relación política androcéntrica y heterosexista-, dan lugar a determinadas lógicas mediáticas que podemos reconstruir a través de las huellas presentes en el discurso.

Según Margullis y Urresti (2005), la juventud es un concepto sociológico situado en condiciones socio-históricas correspondientes a cada época, y lo que persiste en todas es la condición de inestabilidad respecto de las promesas, los temores y las incertidumbres sobre el futuro, siempre en cruce con las urgencias materiales que estas preguntas implican. Los autores hablan entonces de las brechas en las cuales se define la condición juvenil y que tienen que ver con brechas en educación y acceso a la información, pero también a profundas desigualdades en escenarios de asimétrica distribución de recursos y oportunidades.

Este contexto, dirán, configura redes de elecciones posibles / no posibles, y se instituye como el marco de situaciones potencialmente conflictivas donde entran en juego el tiempo y las oportunidades. Así, la sociedad administra posiciones objetivas y podemos pensar que es allí donde los sujetos se juegan enteramente por ocuparlas, rechazarlas, cuestionarlas, transformarlas (2005).

Si antes la ecuación era la del sacrificio como inversión para el acceso al mundo del trabajo -mediante la escolarización-, y la recompensa suponía participación, socialización y consumo; hoy el consumo se presenta como el término más importante dentro de los otros dos. Será el consumo el que echa mano sobre lo mediático, las NTICS y el mercado, y estimula a los jóvenes a una integración comunicativa donde es precisamente el consumo la forma de socialización (2005).

Esta mirada se articula con los planteos de Hopenhayn (2011) y Kessler y Merklen

\footnotetext{
${ }^{6}$ En 2010 se demostró que sólo el 24\% de las personas sobre las que se lee en las noticias son mujeres (en Argentina este indicador asciende al 29\%) y la diferencia de fuentes femeninas según el tipo de noticias presentadas sobre política, gobierno y economía sigue siendo altamente sexista.
} 
(2013) cuando destacan que "la difusión de consumo aparece como agente paradojal en el mundo de la pobreza (...) y esta multiplicación de bienes de consumo variado la invade y atraviesa, cohabita con ella pero no la elimina" (2013, p.16).

Además, Margillis y Urresti dirán que los medios de comunicación exponen a las y los jóvenes al mercado sin garantizar objetivos socializadores, generando así una violencia simbólica de valores para el consumo que homogeneizan, rechazan la diferencia (o la 'marketinizan') y ratifican el sentido común. Lo que está en juego para las y los jóvenes en este contexto no es sólo la posibilidad de inclusión (o no), sino la libertad de elegir, la posibilidad de imaginarse en otro tiempo, y es precisamente allí donde se les expropia el tiempo de vida (2005).

Cuando los medios invisibilizan las expectativas y presiones que operan desde el mercado sobre las juventudes y sólo transmiten prescripciones respecto de las juventudes, nos encontramos frente a una lógica mediática que, en una doble valencia, estereotipa y deshistoriza a los sujetos juveniles.

\subsection{LAS TENDENCIAS EN LOS ESTUDIOS DE JUVENTUD}

La tendencia actual en los estudios críticos sobre las juventudes viene planteando sostenidamente una crítica a la analogía jóvenes=consumidores. Sin embargo, poco se dice sobre la analogía jóvenes= productores y reproductores de roles y estereotipos, y mucho menos (excepto contadas excepciones) sobre aquellos roles y estereotipos de género presentes tanto en la heteropercepción construida desde los medios como en la autopercepción juvenil mediatizada desde una perspectiva sociosemiótica que analice los sentidos construidos alrededor de ciertas palabras, silencios e imágenes, sin quedar en la superficialidad de la representación literal de estas mismas palabras e imágenes. ${ }^{7}$

Desde nuestro enfoque recuperamos, de la tradición sociosemiótica, el estudio de los discursos mediáticos porque esta perspectiva discursiva, al indagar sobre el funcionamiento de la cultura, se opone al mecanicismo materialista y el idealismo lingüístico - constructivista-, para abordar el funcionamiento de los discursos sociales en su densidad material e histórica, atendiendo a las relaciones constitutivas con el sistema de reglas que los tornan inteligibles (Boria y Boccardi, 2013, p.15). Asumimos la perspectiva de análisis sociosemiótica como forma válida para el análisis de los fenómenos sociales, ya que no conduce a la mera descripción de los materiales, sino que nos orienta en el análisis sobre las operaciones de su producción (Verón). Partimos entonces del vínculo indisoluble entre las relaciones de poder -como relaciones de fuerza y por tanto como conjuntos de estrategias (Foucault) - y la producción de sentido socialmente construido (Verón, 1987; Angenot, 2010; Williams, 1980).

Los estudios sobre juventudes y medios insisten en desvincularles de las decisiones vitales que van adoptando, y despojarles de capacidad crítica y poder de decisión. Vale decir, a veces, las propuestas de integrar a los y las jóvenes como protagonistas terminan circunscribiéndoles a ser protagonistas consumidores de coberturas menos dañinas y les consideran sujetos de protección en lugar de sujetos productores de contenidos. ${ }^{8}$

Estamos ante un proceso de mediatización a gran escala donde los medios no sólo están involucrados en "contarnos lo que pasa" sino en establecer un marco de creencias y de representaciones. Los jóvenes son protagonistas en la transformación cultural de las ciudades latinoamericanas $y$, sin embargo, las imágenes que de ellos/as recibimos son altamente despolitizadas, poco proactivas y proyectivas, y sexistas.

La investigadora Florencia Saintout (2005) explica que los discursos que construyen la condición de juventud a través del poder de nombrar oscilan entre el éxito y la desconfianza, con término medio en la amenaza. Así, podemos resumir tres estereotipos y estigmatizaciones que los medios de comunicación

\footnotetext{
${ }^{7}$ Desde este planteo nos distanciamos de los estudios sobre el sexismo de la lengua para provocar una mirada insidiosa sobre aquellas dimensiones del lenguaje que lo constituyen como arena del sentido social, espacio de disputa de otras luchas sociales. Nos situamos en el plano del lenguaje para acceder desde allí a las condiciones socio históricas de producción del sentido y analizamos los macrofuncionamientos discursivos que sobredeterminan los microfuncionamientos lingüísticos.

${ }^{8} \mathrm{Al}$ respecto, puede consultarse el Seminario para Especialistas de la Unión Europea "Los niños y los jóvenes en el nuevo panorama de los medios" (COMFER 2001), recuperado el 15 de septiembre de 2013 de http://www.afsca.gob.ar/Varios/Estudios/Contenido_en_los_medios/seminario.pdf
} 
construyen sobre los varones jóvenes:

- Exitosos: Consumidores, espléndidos en lo físico, desenvueltos en el amor y amistosos. No se preguntan por lo político, vienen de un modelo económico político neoliberal, de surgimiento de las industrias culturales, y emergencia de las culturas juveniles.

- Desinteresados (Ni Ni): caracterizados por la apatía y vulnerabilidad. El ocio como dimensión de socialización en lo público. Individualistas y descontrolados, que sólo identifican los códigos de sus pares.

- Peligrosos: quienes nada tienen que perder. Se comportan de manera salvaje y hacen peligrar la vida, la paz, el orden y el territorio.

Según un informe del Observatorio de Jóvenes, Comunicación y Medios de la Facultad de Periodismo y Comunicación Social de la UNLP (2013), las configuraciones mediáticas sobre jóvenes suceden sincrónicamente a otras producidas por las agencias de control penal -la justicia y las fuerzas de seguridad-, que accionan violentamente sobre y contra los y las jóvenes. Replican el paradigma del Patronato que funcionó como marco jurídico/ político de tutelaje del Estado durante casi todo el siglo XX y que recientemente ha comenzado a virar hacia una perspectiva de Promoción de Derechos que todavía no tiene en los medios un correlato significativo. Bajo el paradigma tutelar, los niños, niñas y adolescentes son objetos de derecho, adultos incompletos/as -y por lo tanto incapaces- cuyos intereses deben ser preservados por otros sujetos que se presentan como completos y capaces: los adultos. Esa es la lógica que prima en las narrativas mediáticas, a contramano de los avances jurídicos que incorporan a los y las jóvenes como sujetos de derecho.

Esta criminalización mediática sobre la peligrosidad juvenil supone corrección o eliminación de sujetos/rasgos indeseables, otorga funcionalidad y condiciones de inteligibilidad a discursos dominantes que tildan a Ixs jóvenes de peligrosos, y podemos decir que esta práctica mediática es profundamente antidemocrática (Urresti y Margullis, 2005).

Por su parte la imagen de las mujeres jóvenes en los medios aparece asociada a tres ejes:

- La belleza y el erotismo: Los sujetos juveniles femeninos son leídos como cuerpos disponibles para el deseo y placer. Se les despoja de toda práctica que no tenga relación con la frivolidad consumista, invisibilizando inquietudes e intereses que impliquen autonomía de criterio y decisión.

- La maternidad adolescente: La imagen de la maternidad joven se construye mediáticamente en una doble valencia. La glorificación de la misma y la estigmatización de sujetos jóvenes sexualizados precozmente. Ambas operaciones coinciden en el borramiento de la violencia sexual y de la inequidad en el ejercicio de derechos sexuales y reproductivos, y en presentar la concepción como un proceso inmodificable por la mujer.

- La violencia y la delincuencia: En ocasiones aparecen en los medios imágenes de jóvenes violentas. Se asocia su agresión a una hipersexualización y falta de valores, y se pone en duda la capacidad de las mujeres jóvenes para identificar a un agresor y defenderse ante situaciones de violencia de género.

\subsection{LOS ESTUDIOS SOBRE JUVENTUD Y LA PERSPECTIVA DE GÉNERO}

En el campo de los estudios críticos de juventud, en Argentina, podemos reconocer el cruce género y juventud a través de los trabajos de Silvia Elizalde (2003) como un antecedente de referencia. Para la autora, la indagación sobre las mujeres jóvenes, su relación con los discursos y estrategias públicas y los cambios operados en sus modalidades de construcción identitaria, siguen siendo áreas proporcionalmente menos exploradas en los corpora de las investigaciones sociales. Su trabajo indaga, desde la trama productiva del discurso autobiográfico, los modos en que las jóvenes responden críticamente a las imágenes socialmente construidas en torno de su condición genérica y etaria -que las suelen ubicar en situaciones de mayor precariedad que sus pares varones para el acceso a las oportunidades sociales-, en el uso placentero de su sexualidad y la participación comunitaria. En este punto la autora desarrolla la línea "Parodiar el estigma, politizar el cuerpo", e inaugura toda una serie de interrogantes sobre los temas que las jóvenes piensan y discuten (como la sexualidad, la relación con sus cuerpos y las distintas formas en que experimentan la represión y el control por parte del entorno social y vecinal que habitan).

Por su parte, la diversidad y la disidencia sexual casi nunca aparecen representadas 
mediáticamente, y cuando aparecen, excepcionalmente, lo hacen vinculadas a procesos biologicistas y jurídicos de cambio y reasignación de sexo.

Con motivo del segundo informe Representaciones de género en los informativos de radio y televisión (2005) realizado en España por la investigadora Pilar López Diez y su equipo, se elaboró la categoría Representaciones de género como una categoría analítica apropiada para el análisis de emisiones radiales y televisivas. ${ }^{9}$ En la investigación se aplicó la categoría prestando atención a dos aspectos:

El primero tuvo en cuenta los temas de las noticias analizadas y la aparición de las mujeres allí (¿Qué tipo de noticias tiene a la mujer como tema central?). El segundo aspecto pretendía considerar, de cada noticia, la representación de género que allí se elaboraba -tanto de las personas productoras del discurso (presentador/a del informativo o telediario; redactor o redactora; corresponsal, enviada/o especial, presentador/a de deportes; comentarista o analista), ${ }^{10}$ como así también la de las personas objeto de la información (como protagonistas, testigos, personas expertas, que hacen declaraciones, que muestran opiniones, testimonios, etc)atendiendo a la variable género.

En este sentido las representaciones de género se nos presentan en el informe como "las imágenes de" -mujeres en este casoreconstruidas a través de tres variables (modos de aparición ya sea mencionadas o entrevistadas, tiempo, y forma en que son presentadas).

Esta propuesta nos parece sumamente interesante y superadora de las trabajadas sobre las representaciones de la juventud en los medios. Si bien en este artículo hemos visto una serie de tipificaciones sobe los sujetos juveniles y sus prácticas, poco y nada se ha investigado sobre el andro-hetero-sexismo comunicacional mediatizado incorporado en estas tipificaciones.

Como dispositivos de saber (Boria y Dalmaso, 2003) los medios participan activamente en procesos de construcción discursiva de las subjetividades legitimando modelos, conductas y actitudes (2003, p. 18) y cristalizan las prácticas humanas en determinados roles disponibles y esperables. El problema en estos procesos radica en que se constituyen como procesos estructurantes y modelan representaciones que se nos presentan como definiciones naturales. Para nosotros los medios son dispositivos de enunciación mediáticos situados en marcos institucionales y condicionamientos políticos históricamente determinados (Verón, 1987).

El contenido mediático es pertinente porque se asocia a una estrategia enunciativa (Verón, 2001) y es así evidente que no hay producción de sentido sin puesta en escena. Es esa puesta en escena, una puesta en sentido de los registros significantes (imagen, voz, cuerpo) (2001, p. 77) que construyen lo real social. Sin embargo, en la red de discursos de un momento determinado podemos notar como lo real es siempre fragmentado y se convierte en lugar de producción de diferencias. Este mecanismo de construcción de lo real es lo que marca agenda, sedimenta estereotipos, y naturaliza la jerarquía en función de los sexos, y los medios operan como mediadores obligados de la gestión política de las representaciones sociales (Verón, 2004).

Pensar la representación juvenil en términos de las asignaciones de sentido que se hacen mediáticamente sobre los sujetos y sus prácticas es un ejercicio que realizamos sobre el corpus de radios y que se inspira en los objetivos del informe español citado. El informe supera la analogía representación=imagen, para preguntarse por el papel que llevan a cabo las mujeres y los hombres en las noti-

\footnotetext{
${ }^{9}$ Con motivo de la investigación, López Díez indicaba que "Según señalan los organismos internacionales que luchan por combatir la discriminación social contra las mujeres, imágenes más diversas e igualitarias de las mujeres pueden ayudar a superar las desigualdades a las que tienen que hacer frente con respecto a los hombres. A partir de la IV Conferencia Mundial de Mujeres en Beijing, que consideró a los medios de comunicación como una de las doce áreas de especial interés para conseguir el objetivo de lograr la igualdad, grupos de mujeres y también organismos gubernamentales se están comprometiendo en una política de sensibilización encaminada a conocer cuáles son las imágenes que los medios construyen sobre las mujeres y los hombres" (2005, p.15).

${ }^{10}$ En este punto también se consideró como estas personas eran mencionadas, se registró a todas las personas (por género) de las que hablaba la noticia, mencionadas por su nombre propio; se analizó si ingresaban a la noticia como personas entrevistadas o no; se registró el número de veces que han hablado las personas en cada noticia; el tiempo total que las personas (por género) han intervenido con su voz; y la forma en que ha sido tratada cada una de las personas en cuanto a: estatus vicario, víctima, acusada, o reconocimiento.
} 
cias audiovisuales, los puestos que ocupan en la sociedad, los temas o asuntos públicos en que unas y otros tienen mayor o menor presencia y la forma en que las noticias muestran a mujeres y hombres, así como el tipo de noticias "diferentes" que podrían cubrir en pos de introducir nuevos modelos de representación de mujeres y hombres más igualitarios, de manera que conseguirán combatir los estereotipos tradicionales y los roles de género con que tratan a las mujeres la mayoría de las noticias de los informativos (2005, p.9).

En nuestro artículo, esta manera de analizar las representaciones se va a sostener en la categoría de andro-hetero-sexismo comunicacional mediatizado.

\section{PERSPECTIVA DE ANÁLISIS Y ENFOQUE METODOLÓGICO}

Si los medios de comunicación trabajan sobre una lógica de fragmentación, es a partir de una epistemología de la reconstrucción que nos proponemos, como lo indican desde el Observatorio de la UNLP, transitar los intersticios y múltiples reversos con que se nombra a lo juvenil en la escena contemporánea.

El enfoque metodológico que nos planteamos en torno al análisis discursivo se inscribe en la perspectiva sociosemiótica (Verón, 1987; Angenot, 2010; Charaudeau, 2002) desde la que es posible preguntarse por la influencia que ejercen las condiciones productivas en el discurso y, por lo tanto, el arraigo de estos últimos en la sociedad y en la evolución histórica. Entendemos entonces que abordar este complejo entramado de condiciones de producción discursivas aporta a identificar cómo se articula la legitimación sociocultural de la jerarquización de género en base a la diferencia sexual, y nos permite ingresar al análisis de las modalidades en las que aparece lo juvenil en las gramáticas de producción discursiva radiofónicas.

Cuando analizamos esta construcción de lo juvenil como procesos intersubjetivos inscritos en relaciones sociales e históricas situadas, en el contexto social y en su relación con lo no juvenil (Balardini, 2004), estamos pensando en la construcción discursiva de subjetividades, donde las representaciones juveniles están marcadas por el adultocentrismo, pero también el sexismo y el androcentrismo enunciativo.

\subsection{ANDRO-HETERO-SEXISMO COMUNICA- CIONAL MEDIATIZADO}

El término androcentrismo fue introducido en el debate sociológico por la estadounidense Charlotte Perkins Gilman con su obra de investigación Nuestra cultura androcéntrica: o el mundo hecho por el hombre, publicada en 1911. Cuando hablamos de androcentrismo -en términos generales -, nos referimos a la visión del mundo que sitúa al hombre como centro de todas las cosas, construye una mirada masculina como universal y única posible y conlleva la invisibilidad de las mujeres y de su mundo, la negación de una mirada femenina, y la ocultación de las aportaciones realizadas por las mujeres. Esta concepción presupone sin embargo una perspectiva un tanto esencialista respecto de lo que se supone es el "mundo de" las mujeres o la "mirada femenina", y nos sitúa precisamente en una concepción de lo androcéntrico asociada a una de las dimensiones que componen el concepto: el sexismo.

Eulalia Lledó, doctora en Filología Románica por la Universidad de Barcelona, aborda el concepto como aquella perspectiva que sustenta y reproduce la hegemonía del sentido respecto a la diferencia sexual, y que habilita a la invisibilización femenina como su correlato más evidente (Lledó, 1996), a través de mecanismos ideológicos que priorizan un punto de vista parcial. La autora explica que esta parcialidad reside en considerar que lo que han hecho los hombres es lo que ha hecho la humanidad, y en creer que la experiencia masculina incluye y es la medida de las experiencias humanas (1996, p. 91).

Creemos que entre ambos términos existe una relación de implicancia dicotómica (Maffía, 2012). Es decir: El sexismo como categoría opera al servicio de la matriz androcéntrica y habilita gramáticas de producción que refuerzan el punto de vista centrado en lo masculino-genérico; y el androcentrismo como perspectiva facilita los marcos de inteligibilidad en los cuales se naturaliza el ejercicio del sexismo, y se potencia su legitimidad simbólica.

Para el punto de vista centrado en lo masculino-genérico, la diferencia sexual se presenta como factor excluyente -aunque no suficiente-, para determinar el ingreso de sujetos a ese dominio universal, porque no es el "sexo" lo que distingue al hombre como ser 
digno de universalidad y dominio expansivo, sino una conjunción de factores que Moreno Sardá desarrolla bajo el concepto de Arquetipo Viril (2007, p. 52).

Retomando nuestra secuencia, el androcentrismo entabla una relación de implicancia dicotómica con el sexismo, y esa dicotomía se presenta a través de dos dimensiones:

1. La complementariedad entre ambos términos (que desarrolláramos anteriormente) $y$

2. El ejercicio de subdividir que se produce hacia el interior del colectivo de sexo masculino para determinar quienes acceden y quienes no al arquetipo viril. Este es un ejercicio de doble exclusión en base al sexo. Al plantear esta segunda división, los varones viriles redistribuyen el poder entre quienes asuman condiciones determinadas de clase, raza, etnia, edad. El sexo, al haber sido el primer filtro, nuevamente ejerce su potencia a través de la violencia de la exclusión simbólica. Este mecanismo de invisibilización sienta las bases ideológicas para que el sexismo goce de aceptabilidad y encanto (Angenot, 2010).

Así, y como parte constitutiva de la matriz androcéntrica de nuestra cultura, ciertas gramáticas de producción (Verón, 2004) actualizan la eficacia simbólica del prejuicio (Bourdieu, 2000, p.6) en la práctica periodística cotidiana y es allí donde las huellas del discurso nos permiten abordar las manifestaciones de sus presupuestos fundantes (como así también su vigencia), y reconocer los modos en que habilitan condiciones socio culturales para la eficacia de la violencia simbólica (Femenías, 2008, p.41).

La Dra. Claudia Laudano (2010) ha desarrollado el concepto de Androcentrismo informativo mediante un lúcido análisis sobre los rasgos sobresalientes del tratamiento periodístico de la violencia de género desde los años 80 hasta la actualidad, precisando los modos predominantes en que la maquinaria informativa otorgó inteligibilidad a los hechos y codificó una gramática singular de la violencia (Laudano, 2010). Explicará la autora que, en la actualidad, dos estrategias retóricas invisibilizan la violencia hacia las mujeres: aquella construida en torno a la imagen de crímenes pasionales, y la que postula la violencia hacia las mujeres y jóvenes como subsidiaria de la política de la inseguridad ciudadana.

En términos metodológicos, Laudano pre- senta varios puntos de coincidencia con López Diez y aborda las rutinas periodísticas desde dos entradas de análisis, construyendo así un marco interpretativo sobre lo que podemos considerar por Androcentrismo informativo:

1. Selección, jerarquización y presentación de Temas.

2. Tratamiento, coberturas y abordajes mediáticos.

Desde nuestra investigación retomamos este enfoque para plantear que lo juvenil es, en radio, una dimensión de análisis de esta Red Semiótica de Violencias Mediáticas que se va configurando en la significación que socialmente le asignamos a los diversos elementos del lenguaje radiofónico. Esto es, dar cuenta de lo juvenil como una dimensión significante de las relaciones de poder entre el género y la edad presente en las construcciones sociodiscursivas sobre los y las sujetos juveniles.

\subsection{RADIO, GÉNERO Y JUVENTUDES. UNA ARTICULACIÓN NOVEDOSA}

Desde 2009 y a través de una serie de trabajos de investigación, extensión y docencia venimos abordando el medio radiofónico desde su dimensión institucional y enunciativa (Matta y Scarafía, 1993; Ammann, 2011). A partir de este enfoque nos hemos propuesto investigar las modalidades de enunciación del lenguaje radiofónico -como sistema semiótico (Balsebre, 1994, p. 27)-, donde se ponen en juego diversas estrategias, tópicas y retóricas.

Entendemos así el medio radiofónico como un sistema semiótico que pone en juego los sistemas expresivos de la palabra, la música, los efectos sonoros y el silencio, en relación con los recursos técnico-expresivos de la reproducción sonora y la percepción del oyente (Balsebre, 1994).

Las voces presentes en el universo sonoro radiofónico analizado constituyen una materialidad discursiva altamente significante. La palabra oral tiene riqueza, complejidad y fuerza expresiva, y su poder significante radica en aspectos denotativos y también connotativos. El poder expresivo de la voz humana, la capacidad de reflejar la tradición oral de los pueblos, de acompañar las temporalidades cotidianas y de operar como instrumento de imaginación e interacción colectiva la sitúan 
en un punto estratégico a la hora de reconocerle potencialidad de análisis. Al hablar de lo radiofónico como un lenguaje donde se inscriben, producen, reproducen y resignifican manifestaciones de nuestra cultura, analizado desde los enfoques interdisciplinares sociosemiótico y de género, estamos aportando al campo de los estudios en comunicación un acercamiento hasta el momento inexplorado: el lenguaje radiofónico, analizado a través de las violencias mediáticas, en clave de género y sociosemiótica.

Cuando asumimos el lenguaje radiofónico como un sistema semiótico (Balsebre, 1994) pudimos desarrollar una mirada sobre la Violencia Mediática (V.M.) en perspectiva y superar los esquemas deterministas y funcionalistas de la representación del lenguaje y la imagen desde el género, asumiendo que, en tanto modalidad de la violencia simbólica, opera por acción y por omisión y se vincula interdependientemente con otros tipos de violencias de género.

Entendemos por V.M. aquel sistema complejo de carácter sociosemiótico donde se configuran mapas de sentido para la interpretación y actualización de la matriz de inteligiblidad de las relaciones de género. Nuestra interpretación excede la VM en tanto manifestación de forma y/o contenido.

La V.M. utiliza la plataforma mediática para su reproducción porque en ella convergen modalidades de enunciación, tópicas, retóricas, saberes técnicos e instrumentales, y tradiciones filosóficas y políticas, voces mediatizadas y tecnología de contacto.

Cuando iniciamos la investigación partimos del supuesto de que: "La V.M. habilitaría en el plano simbólico, la reproducción y naturalización de condiciones para el ejercicio de otras violencias de género en ámbitos sociales considerados privados (familia, relaciones interpersonales)". El problema de la V.M. se nos presentaba como una manifestación ${ }^{11}$ evidente de la actualización de esta tradición cultural.

Tras una revisión crítica de lo anterior hallamos necesario resaltar que es un complejo entramado de condiciones de producción discursivas (Verón, 1987) lo que articula, en el ámbito mediático, la legitimación sociocultural de la jerarquización de las relaciones de género en base a la diferencia sexual. Resituamos así la categoría V.M. en el plano de las manifestaciones de una matriz androcéntrica $y$ heterosexista de nuestra cultura que es la que opera en las representaciones de las relaciones de género, en las condiciones de acceso de las mujeres al sistema mediático, en su permanencia, en los medios disponibles para el desarrollo de condiciones de enunciación en equidad y en el tipo de reconocimiento del campo hacia la presencia significativa de mujeres en él.

Ambos conceptos (androcentrismo y heterosexualidad) son centrales para la investigación y mantienen vigencia justamente al entrar en diálogo con miradas posestructuralistas, ya que tanto el concepto de androcentrismo de Moreno Sardá (2007) -que vincula género con raza, etnia, clase, edad-, como el de heterosexualidad como régimen político (Wittig), tienen aún mucho por dialogar con la propuesta butleriana de punto de ruptura.

Como sistema significante desborda los análisis centrados en la dimensión del lenguaje y nos habilita a repensar el discurso mediático desde los regímenes de visibilidad/ reconocimiento que pone en juego, y los cruces con el dominio de lo público / privado y lo político que desarrolla. La V.M. opera como un sistema porque articula mecanismos de base del funcionamiento social bajo el principio funcional de la violencia de género: Aquella que restaura el orden simbólico a través de múltiples estrategias, combinando los elementos integrantes del sistema, a fin de reproducir su funcionamiento.

Lo anterior nos permite entonces preguntarnos por los modos en que ingresa lo juvenil (Balardini, 2004) en la semiosis social mediatizada (en radio), a través de qué marcos explicativos y qué criterios de inteligibilidad. Nos preguntamos así por las tópicas y retóricas desde las cuales el Androcentrismo mediatizado (Laudano) articula con la dimensión sexo-genérica y de edad, particularmente las referentes a la construcción de sentidos sobre lo juvenil y las juventudes, pero también nos preguntamos por el sexismo en el tratamiento de las fuentes, los tiempos de la palabra en radio según el sexo de los hablantes, qué se dice y qué no se dice sobre las prácticas juveniles, cómo se asocian los consumos ju${ }^{11}$ Lo que Sánchez Leiva define como una concepción representacionalista o correspondencialista del lenguaje
(2007, p. 67). 
veniles a los procesos identitarios, qué temas se asocian a lo juvenil, y qué expectativas sociales se ponen en juego cuando el discurso mediático adultocéntrico habla sobre los y las jóvenes.

\section{LO JUVENIL EN RADIO: LAS REPRESENTA- CIONES DE GÉNERO EN 'DÍA DEL ESTUDIAN- TE' Y 'DÍA DE LA PRIMAVERA'}

\section{1. TEMAS Y RELACIONES DE GÉNERO}

En términos generales, el corpus analizado nos permite constatar que la radio de mayor audiencia (LV3), emisora de carácter eminentemente comercial, relaciona juventud con diversión, y asocia el término con lo que es el clima festivo de la serie televisiva Graduados (que aborda la finalización del ciclo de formación básica para las y los jóvenes) y presenta lo juvenil desde una mirada adultocéntrica y tutelar.

Además, el activismo y la movilización juvenil que se instituyen en reclamos por acceso pleno al sistema de derechos (como es el caso del transporte estudiantil), son abordados desde esta radio como reclamos, y cubiertos literalmente como "una queja".

En el caso de la radio pública (Radio Nacional (ba), la participación activa de una joven cronista en las salidas al aire habilitan comentarios entre los periodistas sobre la importancia de la formación de los y las jóvenes y la participación en los asuntos públicos. Sin embargo, dentro de la agenda de participación ciudadana de Radio Nacional, la presencia de colectivos juveniles está mínimamente representada, lo cual nos resulta muy significativo ya que en la ciudad de Córdoba existen colectivos juveniles con trayectoria y potencia para la participación en el debate discursivo local.

Podemos escuchar la referencia al tema "Juventud y Política" en un pasaje del magazine, pero la referencia a una juventud organizada se asocia a la continuidad de otros momentos históricos que podríamos situar en los años 70 donde la juventud resistió al golpe de estado y su herencia puede verse en la conformación del grupo HIJOS ${ }^{12}$, que, junto al Archivo Provincial de la Memoria, convocan a una ronda de la memoria donde se trabajarán experiencias y producciones artísticas hechas por jóvenes. Los jóvenes de hoy serían los participantes de la actividad entonces convocada por los jóvenes de los 90, hijos de los jóvenes de los 70 .

Los temas que ingresan a la discursividad mediatizada sobre los jóvenes -en ambas emisoras-, giran por un lado en torno al divertimento/entretenimiento ${ }^{13}$. "Ia fiesta del Día del Estudiante" y, por otro lado, de manera peyorativa y estigmatizante, se habla sobre el consumo de drogas, los accidentes en vía pública y los delitos de robo protagonizados por jóvenes varones ${ }^{14}$.

En el plano del tratamiento mediático, ciertas temáticas y problemáticas significativas para los procesos de subjetivación juveniles, propias de las agendas feministas y de derechos de las mujeres (como lo son el acceso al mundo del trabajo, la división sexual de los ámbitos laborales, la educación sexista, el sesgo androcéntrico en las carreras universitarias, los derechos sexuales y reproductivos, las múltiples violencias de género, etc.) aparecen escasamente en la materialidad radiofónica investigada y, cuando ingresan -excepcionalmente-, son reubicadas en el ámbito de lo privado mediante formatos como la entrevista testimonial/dramática y bajo una mirada adultocéntrica de especialista/experto que presenta y guía el tema.

La retórica inscrita en gramáticas de producción mediáticas, decimos entonces, individualiza y circunscribe la experiencia juvenil como una expresión desvinculada de las condiciones históricas que, en el caso de la agenda de género, se ha construido desde la teoría y el activismo feminista.

En cuanto a la distribución de la palabra pública, del status de ciertas voces en temas que remiten a la política, la filosofía, la econo-

\footnotetext{
${ }^{12}$ HIJOS por la identidad y la justicia, contra el olvido y el silencio, organización compuesta por hijos de detenidos desaparecidos en la última dictadura militar argentina.

${ }^{13}$ Podemos escuchar frases como "vamos a ver los chicos a donde van, a donde vienen...tenemos móviles desparramados por toda la provincia”; el móvil referencia el horario de cierre de venta de alcohol en los sitios festivos; o en Radio Nacional cuando inician el programa anunciando que tendrán móviles en la estación de ómnibus por el intenso movimiento de estudiantes que van a distintos puntos turísticos para festejar el Día de la Primavera y del Estudiante.

${ }^{14}$ Cuando en LV3 se leen los titulares podemos ver la secuencia de sentidos que se construyen al anunciar: "el abuso del alcohol no se habla en casa. A los padres les inquieta el tema pero no creen que sus hijos beban"; luego una noticia referida a los Motochorros, y finalmente información sobre el operativo policial "Primavera segura" en los sitios festivos.
} 
mía y las ciencias, opera una cierta economía política de la distribución de la palabra en el ámbito de lo público que actualiza hábilmente sus estrategias discursivas para reubicar las nuevas identidades juveniles y los nuevos roles de las identidades tradicionales, en el mismo sistema jerárquico de status basado en la diferencia sexual y los roles de género producto de esta. Respecto a la imagen de "mujer joven" y "varón joven" que se construye discursivamente en ambas emisoras, podemos decir que los varones ingresan al mundo de la radio claramente representados a través del discurso deportivo, donde la asociación de lo juvenil se realiza en la secuencia: sujeto joven, por tanto atlético, por tanto promesa del fútbol o con probabilidades de hacer carrera en el deporte.

A su vez la música refuerza sentidos socialmente aceptados respecto de la división sexual del trabajo en base a la diferencia sexual. Esto puede verse - por ejemplo- en dos piezas musicales del mismo día de emisión donde la emisora privada presenta un tango que relata cómo los muchachos jóvenes volvían de la juerga y las obreritas salían a trabajar a la misma hora, donde queda expuesta no sólo la imagen de la mujer en estatus vicario y silente, sino también los modos en que las relaciones de género están planteadas.

\section{CONCLUSIONES}

Tras un análisis de las emisiones radiofónicas entendemos que los modos en que opera la matriz de inteligibilidad mediática cuando presenta y representa a los/las jóvenes, los estereotipos bajo los cuales aparecen representados, las relaciones de género que entre sí se establecen (o deberían establecerse), y la condición de vulnerabilidad juvenil atribuida como un rasgo inmanente de los mismos, habilitan a la reproducción de un universo significante de estigmatización juvenil y diferenciación sexo-genérica -desigual-, hacia dentro de las representaciones sobre el mismo colectivo de jóvenes.

A partir de los análisis precedentes podemos decir que el discurso radiofónico contemporáneo ejerce múltiples violencias mediáticas en ambos planos de análisis (tópicas y retóricas), subrepresentando a las mujeres jóvenes e invisibilizando las tensiones que transitan cotidianamente para el ejercicio de sus derechos sexuales y reproductivos, como así también educativos, laborales y culturales. Entendemos por esto un 'andro-hetero-sexismo comunicacional mediatizado', que en diálogo con el concepto de heteronormatividad (Wittig, 1978), permite un abordaje complejo de la matriz de intelegibilidad cultural de las relaciones de género (Butler, 2001) y juventud. Ya en 1982, Adrienne Rich planteaba en Heterosexualidad obligatoria y existencia lesbiana, la interrelación entre varias instituciones de esta matriz al decir:

Las instituciones que han controlado tradicionalmente a las mujeres - maternidad patriarcal, explotación económica, familia nuclear, heterosexualidad obligatoria- se están viendo fortalecidas por la legislación, por los mandatos religiosos, por las imágenes de los medios de comunicación y por los esfuerzos de la censura (Rich, 1982).

La condición juvenil le permite visibilizar aquellas zonas de tensión donde las fuerzas del mercado, de la cultura, de la política y de la religión luchan por la disputa de los sentidos legítimos sobre el cuerpo juvenil y su función social. El cuerpo de las mujeres jóvenes se ve atravesado, particularmente, por expectativas sociales que tienen su fundamento en la manera en que nuestra cultura concibe las relaciones de género. El cuerpo de las jóvenes se convierte así en un campo de batalla (MaColeré, 2007) simbólica sobre la apropiación de la voluntad reproductiva y los proyectos de vida autónomos.

Nos revela la presencia de altos índices de Andro-hetero-sexismo en las condiciones de producción mediáticas un discurso que construye estereotipia masculina en la imagen del joven peligroso en el espacio público, pero que no repara en los actuales índices de violencia de género hacia las chicas; que le ubica como joven exitoso potencialmente a través del dominio atlético de su cuerpo; y estigmatiza la sexualidad juvenil femenina mediante el señalamiento mediático sobre las mujeres jóvenes que abortan y las presenta como potenciales asesinas; un discurso mediático de marcada erotización de la violencia presente en las piezas publicitarias y ficcionales.

Todas estas son operaciones mediáticas que desvinculan las prácticas juveniles de sus condiciones de producción y que, al individualizarlas, las despolitizan. A través de estas 
operaciones se borran prolijamente las condiciones históricas de lo juvenil y pareciera ser que no existe la posibilidad del devenir de las auto-representaciones en identidades narrativas (individuales y colectivas), en la trama de la sociabilidad y las experiencias históricas situadas (2005, pp. 26-27).

La condición juvenil se desvincula así de su condición sexo-genérica presente tanto en las experiencias juveniles, como en las expectativas socio-culturales sobre los cuerpos juveniles que la matriz biologicista-médica, moralista, jurídico-normativa, y religiosa reinscribe cotidianamente. Se despolitiza la condición juvenil y se oculta el conflicto, constituyendo márgenes mediáticos para el ejercicio de violencias mediáticas de género. Si desde el periodismo no consideramos el conflicto como punto de partida para visibilizar las relaciones de poder, poco podremos decir de las relaciones de género inscritas en las auto y hetero percepciones juveniles mediatizadas.

En este marco de relaciones, y preguntándonos qué se juega de los adultos en la construcción de la categoría jóvenes, observamos que el campo mediático constituye un escenario de proyecciones sobre lo que nuestras culturas aún hoy representan como proyecto de sociedad, de adultez, semilla de la fuerza productiva $-\mathrm{y}$ reproductiva-, moratoria social, intra grupalmente pero también entre jóvenes varones y mujeres, y entre diversas identidades sexuales. Luis Gómez Suárez
(2011) señala al respecto: “Los jóvenes en su imaginación colectiva generan una identidad cuya imagen es reelaborada por la sociedad y devuelta a ellos. Éstos, entonces, se ven a sí mismos como los miran los demás" (2011, p.33). La juventud es, por lo tanto, una condición que se define en otro lugar, pero que admite un vaivén y un reenvío desde las formas de autopercepción y las de heteropercepción. La Encuesta Iberoamericana (2013) registra que los jóvenes se han mostrado más conservadores de lo que se creía en temas como el aborto o la marihuana, lo cual resulta altamente paradojal cuando sabemos que en nuestros contextos latinoamericanos son precisamente ellos y ellas quienes se encuentran más perseguidos y estigmatizados por ambas cuestiones.

Creemos en el agenciamiento juvenil como capacidad fundamental para la articulación entre sujeto y prácticas discursivas, y afirmamos que es desde allí desde donde ingresarán los recursos del lenguaje, la historia y la cultura para posibilitar el devenir de las autorepresentaciones en identidades narrativas (individuales y colectivas) en la trama de la sociabilidad y las experiencias históricas situadas (Arfuch, 2005).

Como lo propone Arfuch, tenemos un desafío y es el de recuperar la dimensión política de los sujetos juveniles en los medios, ${ }^{15}$ e identificar aquellas operaciones que les invisibilizan es un primer paso en ese sentido.

\footnotetext{
${ }^{15} \mathrm{Al}$ respecto puede consultarse el trabajo que se realiza en el Observatorio de Jóvenes, Comunicación y Medios UNLP, donde se entiende a los medios de comunicación como actores políticos con intereses particulares y colectivos sobre el devenir social. En ese sentido, la enunciación mediática constituye un pilar fundamental en los procesos de producción y reproducción de los sentidos en las sociedades contemporáneas. Devenidos en un espacio de poder estratégico, las representaciones de los medios generan imágenes que moldean el modo en que se construye la identidad de los jóvenes (2013, p.19).
} 


\section{$>$ Referencias Bibliográficas}

- Ammann Beatriz, y Da Porta Eva (2011) Jóvenes y Mediatización. Prácticas de comunicación y resistencia. Córdoba, Argentina: Ed. Ferreyra.

- Angenot, Marc. (2010). La historia en un corte sincrónico: literatura y discurso social. En Marc Angenot, Interdiscursividades. De hegemonías y disidencias. Córdoba, Argentina: Ed. UNC.

- Arfuch, Leonor. (2005). Identidades, sujetos y subjetividades. Buenos Aires: Ed. Prometeo Libros.

- Balardini, Sergio. (2004). Jóvenes, tecnología, participación y consumo. Ponencia presentada en el Encuentro Internacional: La juventud internacional desde la perspectiva parlamentaria., Cartagena de Indias. A. E. C. I.

- Balsebre, Armand. (1994). El lenguaje radiofónico. Madrid: Ed. Cátedra.

- Butler, Judith (2001). El género en disputa. Barcelona: Paidós.

- Cavana, María (1995). Diferencia. En Celia Amorós (Dir.), 10 Palabras Clave sobre Mujer. Navarra: Verbo Divino.

- Charaudeau, Patrick (2002). El discurso de información mediática. BarcelonaBuenos Aires: Gedisa.

- Charaudeau, Patrick. (2003). El Discurso de la información: la construcción del espejo social. Barcelona: Gedisa.

- COMFER (2001). Seminario para especialistas de la UE. Los niños y los jóvenes en el nuevo paradigma de los me dios. Recuperado el 15 de septiembre de 2013 de http://www.afsca.gob.ar/Varios/ Estudios/Contenido_en_los_medios/ seminario.pdf

- Colectivo Ma Coleré. (2007). Mi cuerpo es un campo de batalla. Valencia: La Burbuja.

- Consejo Audiovisual de Andalucía (2013). Informe sobre la distribución por sexo de los tiempos de palabra en los informativos de las televisiones públicas andaluzas. Recuperado el 15 de noviembre de 2014 de http://www. consejoaudiovisualdeandalucia.es/actividad/actuaciones/informes/2014/09/ informe-sobre-la-distribucion-por-sexode-los-tiempos-de-pala

- Duarte Quapper, Klaudio. (2000) ¿Juventud o juventudes? Acerca de cómo mirar y remirar a las juventudes de nuestro continente. Última Década, 13

- Eco, Umberto (1979). The role of the reader. Bllomington-Londres: Indiana University Press.

- Elizalde, Silvia. (2003). Diferencias culturales y retóricas de (in)visibilidad.
Respuestas de mujeres jóvenes a los discursos normativos sobre el género y edad. Anclajes, 7, 107-131

- Femenías, María. (2008). Violencia contra las mujeres. En Élida Ponte Sánchez, y María Luisa Femenías, Articulaciones sobre la violencia contra las mujeres. Buenos Aires: Ed. Univ. de la Plata.

- Gómez Suarez, Luis. (2011). La juventud como categoría social. En Colectivo de Autores, Lecturas de la realidad Juvenil Cubana a principios del Siglo XXI. La Habana: Centro de Estudios sobre la Juventud.

- Hall, Stuart. (1981). La cultura, los medios de comunicación y el efecto ideológico. En James Curran et. al., Sociedad y comunicación de masas. México: Fondo de Cultura Económica

- Hopenhayn, Martín, y Sojo Ana (2011). Sentido de pertenencia en sociedades fragmentadas. Buenos Aires: Ed. Siglo Veintiuno.

Kessler, Robert, y Merklen, Gabriel. (2013). Individuación, Precariedad, Inseguridad ¿desinstitucionalización del Presente? Buenos Aires: Paidós.

- Lantos, Nicolás (2013, 23 de julio). Alejo Ramírez, de la Organización Iberoamericana de la Juventud: "Traer la voz de los jóvenes”. Página 12. Recuperado el 23 de julio de 2013 de http://www.pagina12.com.ar/diario/ elpais/1-225057-2013-07-23.html

- Laudano, Claudia. (2010). Visibilidad mediática de la violencia hacia las mujeres: continuidades y cambios en Argentina (1983-2009). Revista Derecho $y$ Ciencias Sociales, 3, 88-110.

- Lledó, Eulalia. (1996). La Construcción del sentido: La Representación en la Lengua. En Ana María Portugal y Carmen Torres (Ed.), Por todos los medios: comunicación y género (pp. 90-96). Santiago de Chile: Isis Internacional.

- López Díez, Pilar (Dir.) (2001). Repre sentación de género en los informativos de radio y televisión. Madrid: IORTV

- López Diez, Pilar (Dir.) (2005). Segundo Informe Representación de Género en los Informativos de Radio y Televisión. Madrid: IORTV

- Maffía, Diana. (2012). Género y Derechos Humanos. Seminario de Doctorado. Carrera de Doctorado Estudios de Género, CEA, UNC. Mayo 2012. Córdoba, Argentina.

- Margullis, Mario, y Urresti, Marcelo. (2005).Desigualdad, Incertidumbres y carencias. Revista Tram(p)as de la Comunicación y la Cultura, 34, 8-15.
- Martínez Lirola, María. (2013). Estudio de la construcción discursiva de la mujeres y los menores inmigrantes en una muestra de noticias de radio. Revista de Estudios Filológicos, 25 Recuperado el 29 de junio de 2015 de https://www. um.es/tonosdigital/znum25/secciones/ estudios-22-mujeres_e_inmigrantes_ en_la_radio.htm

- Matta María C., y Scarafía Silvia. (1993). Lo que dicen las radios. Una propuesta para analizar el discurso radiofónico. Quito: A.L.E.R.

- Morales, Paula (2013) Un análisis sobre el poder androcentrista y heterosexista de nuestra cultura en las gramáticas de producción radiofónicas. I Congreso Internacional de Ciencias Sociales y Humanidades "Perspectivas y debates actuales a 30 años de la democracia", Córdoba, Argentina, 20-22 de noviembre de 2013, (paper)

- Moreno Sardá, Amparo. (2007). De qué hablamos cuando hablamos del hombre. Barcelona: Icaria.

- Munguia Chirino, Diana. (2012). El discurso amoroso en la radio como estrategia comunicativa en control social sobre la mujer (Tesis de licenciatura en comunicación,. Facultad de Estudios Superiores Aragón, UNAM, México.

- Observatorio de Jóvenes, Comunicación y Medios (2013). Informe "Jóvenes Nombrados. Herramientas comunicacionales contra la violencia mediática e institucional". La Plata: Universidad Nacional de La Plata.

- Organización Iberoamericana de Juventud (2013). Encuesta Iberoamericana de Juventudes. Recuperado el 25 de julio de 2014 de http://www.oij.org/ file_upload/publicationsItems/document/20130719163951_42.pdf

- Perkins Gilman, Charlotte. (1911). Ou Androcentric Cultur, or The Man-Made World . Disponible en The Project Gutenberg EBook (2009).

- Reguillo, Rosana (2000). Emergencia de culturas juveniles. Estrategias del desencanto. Buenos Aires: Norma.

- Reguillo, Rosana. (2003). Cascadas: agotamiento estructural y crisis del relato. Pensando la participación juvenil. En José Antonio Pérez Islas, Mónica Valdez González, Madeleinte Gauthier, y Pierre-Luc Gravel (Dir.), Nuevas miradas sobre los jóvenes. México/Quebec. México: Instituto Mexicano de la Juventud.

- Rich, Adrienne. (1982). Heterosexualidad obligatoria y existencia lesbiana. (Trad. Maria-Milagros Rivera Garretas). Denver: Antelope Publications. 


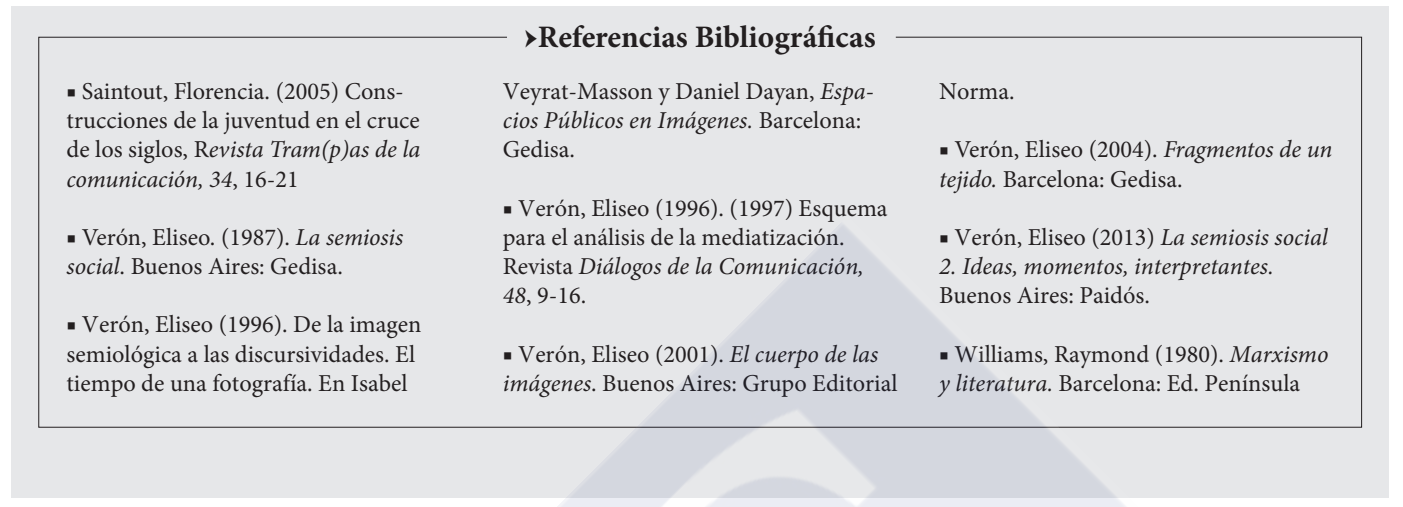

\section{NOTAS BIOGRÁFICAS}

Paula Morales Monguillot es licenciada en Comunicación Social, diplomada en Medios de Comunicación, Violencia Intrafamiliar y Equidad de Género y en Desarrollo Humano con Perspectiva de Género y Derechos Humanos. Actualmente, como becaria doctoral CONICET investiga sobre la Violencia Mediática desde un abordaje socio semiótico, y analiza las relaciones de género en el discurso radiofónico. Es profesora asistente en el taller de Lenguaje II y Producción Radiofónica, y coordinadora del seminario "Comunicación, género y feminismos: la violencia mediática como categoría teórica y problema político en los debates de agenda contemporáneos" (ECI-UNC). Desde 2006 investiga en equipos y programas de investigación sobre Culturas Contemporáneas e Identidades, Mediatización y Prácticas comunicativas juveniles, y Género (SECYT -CEA-UNC).

Contacto: moralesmpaula@gmail.com 